American Journal of Pharmacology and Toxicology 2 (3): 135-139, 2007

ISSN 1557-4962

C 2007 Science Publications

\title{
Cardiovascular Effect of Capparis spinosa Aqueous Extract. Part VI: In vitro Vasorelaxant Effect
}

\author{
${ }^{1}$ N.A. Zeggwagh, ${ }^{2}$ J.B. Michel and ${ }^{1}$ M. Eddouks \\ ${ }^{1}$ UFR PNPE, BP.21, Errachidia, 52000, Morocco \\ ${ }^{2}$ U460 INSERM, faculty of Medicine Xavier Bichat, Paris, France
}

\begin{abstract}
The aim of this study was to investigate the in vitro vasorelaxanteffect of Capparis spinosa Aqueous Extract (CSAE) at a dose of $10 \mathrm{mg} \mathrm{mL}^{-1}$. Aortic rings isolated from normal wistar rats were used. The addition of CSAE during the plateau phase of contraction, induced by noradrenaline and $\mathrm{KCl}$, produced a rapid relaxation. Incubation of aortic ring with CSAE during $30 \mathrm{~min}$ shifted the noradrenaline induced dose response curve $(p<0.001)$ and the maximum response $(p<0.001)$ was attenuated indicating that antagonist effect of the $\alpha 1$ adrenoreceptors was non-competitive. However, endothelium remove significantly reduced the vasorelaxant effect of CSAE $(p<0.01)$. Furthermore, nitric oxide inhibition reduced the vasorelaxant effect of CSAE. However, cyclo-oxygenase inhibition did not affect the vasorelaxant effect of CSAE $(p<0.05)$. Inhibition of L-type voltage dependent Ca2+ channels did not reduce the observed CSAE vasorelaxant effect $(\mathrm{p}<0.05)$. We conclude that CSAE at a dose of $10 \mathrm{mg} \mathrm{mL} \mathrm{m}^{-1}$ possess in vitro vasorelaxant effect which may by mediated via an $\alpha 1$ adrenoreceptors antagonism and/or modulation of nitric oxide synthesis.
\end{abstract}

Key words: Aortic ring, vasorelaxation, endothelium, nitric oxide

\section{INTRODUCTION}

Pharmacological investigations have been supported the traditional use of several medicinal plants in the Moroccan pharmacopoeia ${ }^{[1]}$. Bibliographic survey demonstrated that medicinal plants possess in vitro vasorelaxant effect that may be mediated via different pathways ${ }^{[2-6]}$.

Capparis spinosa (CS) is a plant belonging to Capparidaceae family. According to ethnopharmacological data collected in the southeastern region of Morocco, CS is alleged to possess a hypoglycaemic effect, which has been experimentally demonstrated $\mathrm{d}^{[7,8]}$. Furthermore, it has been reported that some species of the genus Capparis possess molluscicidal activity ${ }^{[9]}$, chonroprotective effect ${ }^{[10]}$ and in vitro antitumour effect ${ }^{[11]}$.

Nevertheless, there is no scientific report on the in vitro vascular effect of CS. Thus, we considered interesting to complete our previous in vivo works (unpublished data) by the in vitro study.

The present study aims to examine the in vitro effect of the Capparis spinosa aqueous extract (CSAE) on the vasomotor tone of aortic rings isolated from normotensive rats.

\section{MATERIALS AND METHODS}

Plant material: Specimens of CS (Capparidaceae) were collected from the Tafilalet region (semi-arid area) of Morocco in May-June 2004 and air-dried at $40^{\circ} \mathrm{C}$. The plant was previously identified and authenticated by Prof M. Rejdali (Agronomy and Veterinary Institute, Rabat) and a voucher specimen (ME 60) was deposited at the herbarium of the Faculty of Sciences and Techniques Errachidia.

Preparation of the aqueous extract: one $g$ of powdered fruits mixed with $100 \mathrm{ml}$ distilled water were boiled for $10 \mathrm{~min}$ and then cooled for $15 \mathrm{~min}$. thereafter, the aqueous extract was filtered using a Millipore filter (Millipore $0.2 \mathrm{~mm}$, St Quentin en Yvelines, France) to remove particulate matter. The filtrate was then freeze-dried and the desired dose (mg of lyophilized aqueous CS extract fruits per kg body weight) was then prepared and reconstituted in saline just before administration. The extract was green coloured with a percent yield of $14 \%$, its average osmolarity was $32 \mathrm{mOsm}, \mathrm{pH} 6.5$ and with a very low viscosity. 
Experimental animals: Healthy adult rats wistar rats, 250-350 $\mathrm{g}$ were used in this study. All rats were maintained at a constant temperature $\left(24 \pm 1^{\circ} \mathrm{C}\right)$, with a $12 \mathrm{~h}$ dark-light cycle and on standard chow.

Aortic ring preparation: The rats were anesthetized with pentobarbital sodium $\left(50 \mathrm{mg} \mathrm{kg}^{-1}\right.$ of body weight, ip) and the thoracic aorta was isolated, cleaned of fat and connective adipose tissue and cut into 3-5 mm long rings. The rings were suspended horizontally in tissue chambers containing $10 \mathrm{~mL}$ of Krebs physiological solution of following composition (mM): $\mathrm{NaCl} 118.2$, $\mathrm{KCl} 4.7, \mathrm{CaCl}_{2} 2 \mathrm{H}_{2} \mathrm{O}$ 2.5, $\mathrm{MgSO}_{4}$ 25.0. Special care was taken to avoid damage of the endothelium. The tissue bath solution was aerated continuously with $95 \%$ $\mathrm{O}_{2}-5 \% \mathrm{CO}_{2}$ at $37^{\circ} \mathrm{C}$. Aortic ring were allowed to equilibrate at an optional tension of $2 \mathrm{~g}$ for $60 \mathrm{~min}$; during this period Krebs solution was replaced every 10 min. In some experiments the endothelium was mechanically removed by gentle rubbing the inner surface of the ring. The absence of endothelium was verified by adding Acetylcholine $\left(10^{-6} \mathrm{M}\right)$ in aortic rings previously contracted by Norepinephrine $\left(10^{-6}\right)$.

Before starting experimental protocol contractile responsiveness of the aortic rings were tested by exposure to Norepinephrine $\left(10^{-6} \mathrm{M}\right)$.

After $60 \mathrm{~min}$ of equilibration, the following experiments were performed;

To determine whether CSAE could relax an existing contraction, aortic rings were contracted by a single concentration of Norepinephrine $\left(10^{-6} \mathrm{M}\right)$ or $\mathrm{KCl}$ $(80 \mathrm{mM})$. When the contractile response to either agonist was stable, CSAE was added at a dose of $10 \mathrm{mg}$ of lyophilized CSAE $\mathrm{mL}^{-1}$ of Krebs solution.

In other experiments, CSAE was incubated with the aortic ring for $30 \mathrm{~min}$ and Norepinephrine was added in progressively increasing cumulative concentration $\left(10^{-10}, 10^{-9}, 10^{-8}, 10^{-7}, 10^{-6}\right.$ and $\left.10^{-5} \mathrm{M}\right)$.

To investigate the effects of CSAE on the endothelium relaxation, CSAE was incubated with endothelium-intact $\mathrm{E}(+)$ and denuded aortic preparations $\mathrm{E}(-)$ for $30 \mathrm{~min}$.

The involvement of the endothelium-related vasorelaxation factors in the CSAE induced vasorelaxation was examined in intact aortic ring pretreated with nitric oxide synthase inhibitor, $\mathrm{N}^{\omega}$-Nitro-LArgenine Methyl (L-NAME) $(30 \mu \mathrm{M})$ or with nonselective cyclo-oxygenase inhibitor, indomethacin $(10 \mu \mathrm{M})$.

The effect of CSAE on the Voltage Operated Channels VOC was studied in aortic ring previously treated during 30 min with a voltage-dependent $\mathrm{Ca}^{2+}$ - channels inhibitor, diltiazem. CSAE was then incubated in the presence or absence of diltiazem.

Statistical analysis: Results were expressed as a percentage changes from the initial pre-contraction level and as mean \pm S.E.M for determinations obtained from six different animals. Analysis of variance (ANOVA) followed by student's t-test was used for statistical analysis. $\mathrm{p}<0.05$ values were considered to present a significant difference. Concentration-response curves were analysed by non-linear regression (GraphPad prism).

Drugs: Acetylcholine chloride, Norepiunephrine, $\mathrm{N}^{\omega}$ nitro-L-argenine methyl (L-NAME) and indomethacin were purchased from Sigme Chemical Co (St. Louis, USA) and dissolved in Krebs solution.

\section{RESULTS}

Effect of CSAE on the $\mathrm{KCl}$ and Norepinephrine plateau contraction: Addition of $\mathrm{KCl}(80 \mathrm{mM})$ or Noradarenaline (NA) $\left(10^{-6} \mathrm{M}\right)$ produced a contractile response with an average of $42 \pm 0.33$ and $52 \pm 1.23 \%$ increase in the baseline vascular tonus respectively. Figure 1a and $\mathrm{b}$ show that CSAE at a dose of $10 \mathrm{mg}$ $\mathrm{mL}^{-1}$ produced an inhibition of the contractile response induced by both stimulatory agents $(\mathrm{KCl}$ and $\mathrm{NA}$ ) $(p<0.001)$. This effect was observed within 15 min after addition of the extract into the bathing solution. Furthermore, the relaxation induced by CSAE was endothelium dependent since the effect of CSAE was significantly decreased in the endothelium denuded aortic ring.

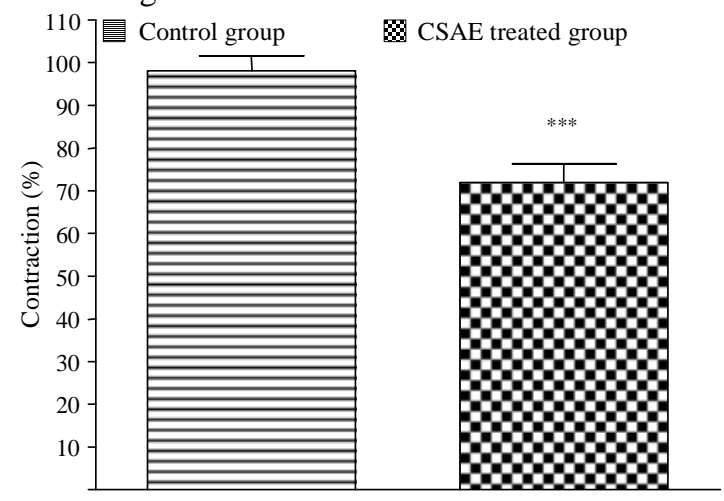

Fig. 1a: Effect of CSAE at a dose of $10 \mathrm{mg} \mathrm{mL}^{-1}$ addition in the plateau contraction induced by Noradrenaline $\left(10^{-6} \mathrm{M}\right)$ in aortic ring. Results are expressed as percentage of maximum response obtained 
in untreated group *: $\mathrm{p}<0.05 * * *: \mathrm{p}<0.001$ When compared with control group.

Control group ;

CSAE treated

group.

Effect of CSAE incubation on the dose response on aortic ring to NE: Figure 2 shows the effect of $30 \mathrm{~min}$ incubation of CSAE at a dose of $10 \mathrm{mg} \mathrm{mL}^{-1}$ on the cumulative concentration-contraction curves to Noradarenaline in endothelium intact rings of aortic rings to NE cumulative dose (from 10-10 to $10-5 \mathrm{M}$ ). CSAE produced significant right shift of the concentration contraction curve $(\mathrm{p}<0.001)$. In addition, CSAE produced a significant reduction of $\mathrm{pD} 2$ values of Noradarenaline and aortic ring maximal response $(\mathrm{p}<0.001)$ as it is shown in Table 1.

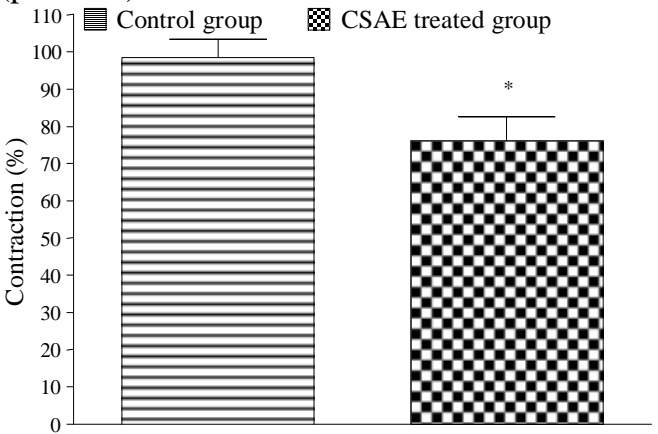

Fig 1b: Effect of CSAE at a dose of $10 \mathrm{mg} \mathrm{mL}^{-1}$ addition in the plateau contraction induced by $\mathrm{KCl}$ $(80 \mathrm{mM})$ in aortic ring. Results are expressed as percentage of maximum response obtained in untreated group *: $\mathrm{p}<0.05 * * *: \mathrm{p}<0.001$ When compared with control group.

Control group ;

CSAE treated

group.

Table 1: In vitro effect of CSAE on the concentrationresponse curve to Noradrenaline in rat aorta. $\mathrm{pD}_{2}(-\mathrm{Log}$ ED50) and maximum response were calculated by nonlinear regression of experimental data. Maximum response is expressed as a percentage of the maximum contraction obtained in the first stimulation to Noradrenaline.

\begin{tabular}{lcll}
\hline & Control & $\begin{array}{l}\mathrm{CSAE} \\
\left.\mathrm{mL}^{-1}\right)\end{array}$ \\
\hline $\mathrm{pD}_{2}$ & $6.17 \pm 0.06$ & $7.24 \pm 0.03 * * *$ \\
$\begin{array}{l}\text { Maximum } \\
\text { contraction }\end{array}$ & $82.78 \pm 2.40$ & $104.21 \pm 1.35 * * *$ \\
\hline$* * *: \mathrm{p}<0.001$ when compared to control group
\end{tabular}

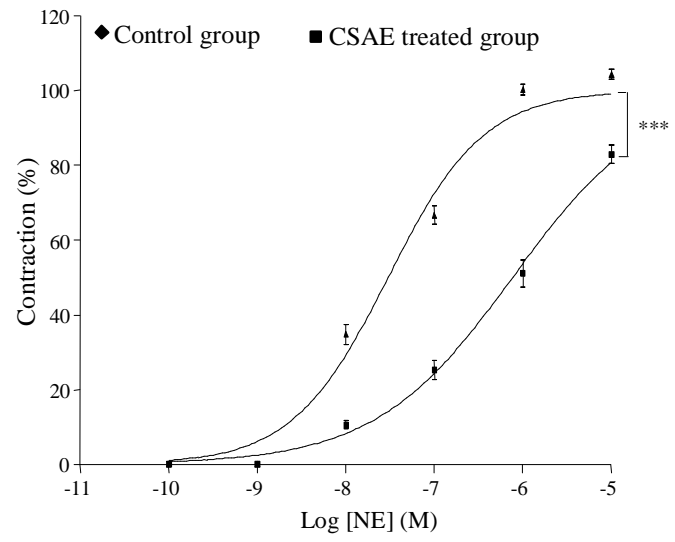

Fig 2: Effect of CSAE at a dose of $10 \mathrm{mg} \mathrm{mL}^{-1}$ on the concentration response of noradrenaline in aortic ring. Results are expressed as a percentage of the maximum response obtained before the incubation of CSAE. ***: $\mathrm{p}<0.001$ when compared with control group.

Control group ; $\quad$ CSAE treated

group

In order to analyse the involvement of endothelium in the CSAE effect, CSAE was incubated with endothelium intact and endothelium denuded preparation. The effect of endothelium in the effect of CSAE is shown in Fig. 3a. Endothelium ablation produced a significant reduction in the vasorelaxant effect of CSAE at a dose of $10 \mathrm{mg} \mathrm{mL}^{-1}(\mathrm{p}<0.001)$.

The effect of nitric oxide synthase inhibition on CSAE effect is shown in Fig. 3b. Inhibition of nitric oxide synthase with LNAME significantly depressed the relaxation evoked by CSAE incubation $(\mathrm{p}<0.001)$. However, treatment of aortic ring with endomethacine did not affect the vasorelaxant effect of CSAE as it is shown in Fig. 3c.

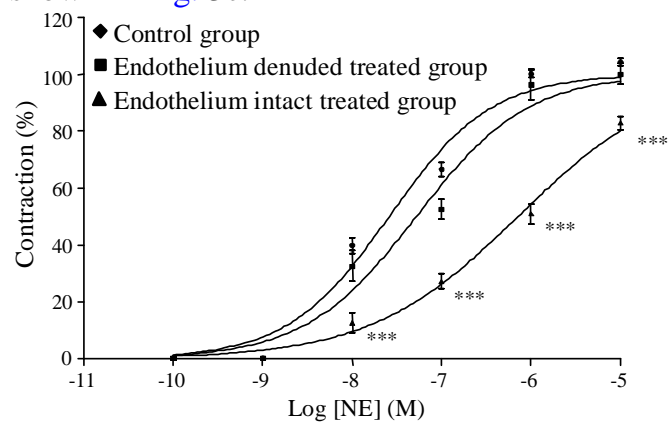

Fig 3a: Effect of CSAE at a dose of $10 \mathrm{mg} \mathrm{mL}^{-1}$ on the concentration response of noradrenaline in endothelium intact and denuded aortic ring. Results are expressed as a percentage of the maximum response obtained before the incubation of CSAE. (***: $p<0.001$ 
Am. J. Pharm. \& Toxicol., 2 (3): 135-139, 2007

Endothelium intact group versus endothelium denuded aortic group).

treated group;

Control group; Endothelium denuded

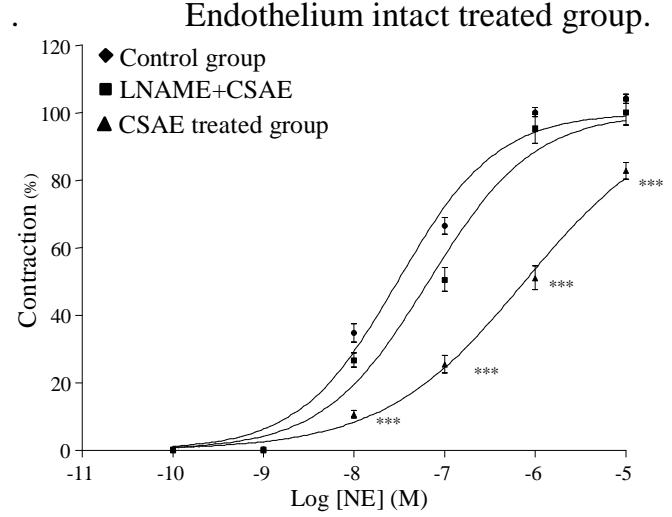

Fig 3b: Effect of CSAE at a dose of $10 \mathrm{mg} \mathrm{mL}^{-1}$ on the concentration response of noradrenaline in LNAME treated (LNAME + CSAE) and CSAE treated aortic ring.( Results are expressed as a percentage of the maximum response obtained before the incubation of CSAE. (***: $\mathrm{p}<0.001$ LNAME treated group versus LNAME untreated group.

Control group; $\quad$ LNAME+CSAE ;

CSAE treated group.

To investigate a possible relation between the relaxation caused by CSAE and inhibition of L-type voltage dependent $\mathrm{Ca}^{2+}$ channels (VOC) was analysed. Figure 4 shows the effect diltiazem treatment on the vasorelaxant effect of CSAE. The results demonstrated that diltiazem did not produce a significant change in the vasorelaxant effect of CSAE.

\section{DISCUSSION}

The contraction generated by noradrenaline is the complex result of the mobilisation of both intracellular and extracellular $\mathrm{Ca}^{2+}$ and the $\mathrm{Ca} 2+$ sensitisation of the contractile machinery ${ }^{[12]}$. Noradrenaline contraction is characterised by the phasic component to depend on calcium release from intracellular stores while the tonic component depends on calcium flux and activation of several proteins such as protein kinase C PKC ${ }^{[13,14]}$. $\mathrm{KCl}-$ evoked contraction results from the entry of $\mathrm{Ca}^{2+}$ through voltage-operated $\mathrm{Ca} 2+$ channels $^{[14]}$. The present study showed that CSAE at a dose of $10 \mathrm{mg}$ $\mathrm{mL}^{-1}$ elicited a potent in vitro vasorelaxant effects in aorta isolated from wistar rats. Addition of CSAE in Noradrenaline and $\mathrm{KCl}$ plateau contraction caused a rapid reduction in aortic tone. In addition, incubation of CSAE during $30 \mathrm{~min}$ significantly reduced the concentration-response curve of Noradrenaline. The maximum response to noradrenaline was attenuated by the presence of CSAE, indicating the antagonistic effects of this extract on vascular smooth muscle cell. So, CSAE may produce vasorelaxation via $\alpha_{1-}$ adrenoreceptors non competitive antagonisms. Previous studies demonstrated similar vasorelaxant effect ${ }^{[2,3,15,16]}$. Endothelium plays a crucial role in the smooth muscle vasorelaxation $^{[12]}$, several studies confirmed the involvement of this vascular part in the pathophysiology of hypertension ${ }^{[14]}$. The effect was dependent on the endothelium, since mechanical remove of endothelium significantly attenuated the vasorelaxant effect of CSAE. Thus CSAE may act throughout same endothelial relaxantfactors (Nitric oxide or prostacyclins) to produce vasorelaxation.

Nitric oxide and prostacyclins are the two major endothelium factors involved in the vasorelaxation ${ }^{[14]}$. It is now clearly established that the pharmacological inhibition of these two factors lead to vasoconstrictive response of aortic ring ${ }^{[4,15,17]}$. To gain more insight in the implication of endothelium in the CSAE-induced relaxation, LNAME and indomethcin have been used respectively to block the NO and prostacyclinsproduction pathway ${ }^{[12,14]}$. Our results show that the CSAE vasorelaxant effect was affected by LNAME treatment indicating the possible involvement of nitric oxide synthesis in the vasorelaxant effect of CSAE as it has been reported in the vasorelaxant effect of other plant extracts ${ }^{[2,15,18,19,20]}$. The vasorelaxant effect of CSAE was not attenuated in the presence of dilatizem (calcium antagonist) indicating that the observed vasorelaxant effect was nor attributed to the blockage of VOC $^{[12,14]}$. In our previous works, we established the in vivo hypotensive and diuretic effect of CSAE in normal rats after both oral and intravenous administration (unpublished data). The present work may give further support and explanations to the reduction in arterial blood pressure after intravenous CSAE injection.

We conclude that CSAE exerts a potent vasorelaxant effect that may be attributed to $\alpha_{1}$-adrenoreceptors non competitive antagonism action. Moreover, CSAE also act as modulator of NO induced relaxation. Further phytochemical experiments are required to investigate its potential vasorelaxant activity and to indentify the active principle(s) responsible for the vascular activity.

\section{REFERENCES}

1. Bellakhdar, J., R. Claise, J. Fleurentin and C. Younos, 1991. Repertory of standard herbal drugs in the moroccan pharmacopoea Journal of Ethnophamacology, 35: 123-43. 
2. El-Hilaly, J., B. Lyoussi, M. Wibo and N. Morel, 2004. Vasorelaxant effect of the aqueous extract of Ajuga iva in rat aorta. J. Ethnopharmacol., 1 (93): 69-74.

3. Ferreira, H.C., C.P. Serra, V.S. Lemos, F.C. Braga and S.F. Cortes, 2007. Nitric oxide-dependent vasodilatation by ethanolic extract of Hancornia speciosa via phosphatidyl-inositol 3-kinase. Journal of Ethnopharmacology, 1 (109): 161-64.

4. Guerrero, M.F., R. Carron, M.L. Martin, L. San Roman and M.T. Reguero, 2001. Antihypertensive and vasorelaxant effects of aqueous extract from Croton schiedeanus Schlecht in rats. Journal of Ethnopharmacology, 75: 33-36.

5. Guerrero, M.F., P. Puebla, R. Carron, M.L. Martin and L. San Roman, 2004. Vasorelaxant effect of new neo-clerodane diterpenoids isolated from Croton schiedeanus. Journal of Ethnopharmacology, 1 (94): 185-89.

6. Testai, L., S. Chericoni, V. Calderone, G. Nencioni, P. Nieri, I. Morelli and E. Martinotti, 2002. Cardiovascular effects of Urtica dioica L. (Urticaceae) roots extracts: in vitro and in vivo pharmacological studies. Journal of Ethnopharmacology, 1 (81): 105-09.

7. Eddouks, M., A. Lemhadri and J.B. Michel, 2004. Caraway and caper: potential anti-hyperglycaemic plants in diabetic rats. J. Ethnopharmacol., 1 (94): 143-8.

8. Eddouks, M., A. Lemhadri and J.B. Michel, 2005. Hypolipidemic activity of aqueous extract of Capparis spinosa L. in normal and diabetic rats. J. Ethnopharmacol., 3 (98): 345-50.

9. Mantawy, M.M., M.A. Hamed, E.M. Sammour and M. Sanad, 2004. Influence of Capparis spinosa and Acacia arabica on certain biochemical haemolymph parameters of Biomphalaria alexandrina. J. Egypt. Soc. Parasitol., 2 (34): 65977.

10. Panico, A.M., V. Cardile, F. Garufi, C. Puglia, F. Bonina and G. Ronsisvalle, 2005. Protective effect of Capparis spinosa on chondrocytes. Life. Sci., 20 (77): 2479-88.

11. Wu, J.H., F.R. Chang, K. Hayashi, H. Shiraki, C.C. Liaw, Y. Nakanishi, K.F. Bastow, D. Yu, I.S. Chen and K.H. Lee, 2003. Antitumor agents. Part 218: Cappamensin A, a new In vitro anticancer principle, from Capparis sikkimensis. Bioorg Med. Chem. Lett., 13 (13): 2223-5.

12. Karaki, H., H. Ozaki, M. Hori, M. Mitsui-Saito, K. Amano, K. Harada, S. Miyamoto, H. Nakazawa, K. J. Won and K. Sato, 1997. Calcium movements, distribution and functions in smooth muscle. Pharmacol. Rev., 2 (49): 157-230.

13. Vandier, C., J.Y. Le Guennec and G. Bedfer, 2002. What are the signaling pathways used by norepinephrine to contract the artery? A demonstration using guinea pig aortic ring segments. Advan. Physiol. Edu., 26: 195-203.

14. Bolton, T.B., 1978. Mechanism of action of transmitters and other substances on smooth muscles. Physiological Reviews, 59: 606-718.

15. Fatehi, M., T. M. Saleh, Z. Fatehi-Hassanabad, K. Farrokhfal, M. Jafarzadeh and S. Davodi, 2005. A pharmacological study on Berberis vulgaris fruit extract. Journal of Ethnopharmacology, 1 (102): 46-52.

16. Aqel, M.B., M.N. Gharaibah and A.S. Salhab, 1991. Direct relaxant effects of garlic juice on smooth and cardiac muscles. Journal of Ethnopharmacology, 1-2 (33): 13-19.

17. Guerrero, M.F., P. Puebla, R. Carron, M.L. Martin, L. Arteaga and L.S. Roman, 2002. Assessment of the antihypertensive and vasodilator effects of ethanolic extracts of some Colombian medicinal plants. Journal of Ethnopharmacology, 1 (80): 3742.

18. Baragatti, B., V. Calderone, L. Testai, E. Martinotti, S. Chericoni and I. Morelli, 2002. Vasodilator activity of crude methanolic extract of Gentiana kokiana Perr. et Song. (Gentianaceae). Journal of Ethnopharmacology, 3 (79): 369-72.

19. Ashraf, M.Z., M.S.Y. Khan, H.A. Hameed, M.E. Hussain and M. Fahim, 1999. Endothelium modulated vasorelaxant response of a polypharmaceutical herbal drug (lipotab) and its individual constituents. Journal of Ethnopharmacology, 1 (66): 97-102.

20. Ashraf, M.Z., M.E. Hussain and M. Fahim, 2004. Endothelium mediated vasorelaxant response of garlic in isolated rat aorta: role of nitric oxide. Journal of Ethnopharmacology, 1 (90): 5-9. 